\title{
Continuous renal replacement therapy in elderly with acute kidney injury
}

\author{
Kristianne Rachel P. Medina-Liabres and Sejoong Kim
}

\begin{abstract}
Department of Internal Medicine, Seoul National University Bundang Hospital, Seongnam, Korea
\end{abstract}

Received: December 17, 2019 Accepted: February 13, 2020

\section{Correspondence to}

Sejoong Kim, M.D.

Department of Internal Medicine, Seoul National University Bundang Hospital, 82 Gumi-ro 173beon-gil, Bundang-gu,

Seongnam 13620, Korea

Tel: +82-31-787-7051

Fax: +82-31-787-4052

E-mail: sejoong@snubh.org

https://orcid.org/0000-00027238-9962
The objective of this article is to raise awareness among physicians of the increasing incidence of acute kidney injury in the elderly population and the utility of continuous renal replacement therapy (CRRT) in its management. While CRRT is frequently applied in younger patients, its use in elderly patients is less frequent, for various reasons, including resistance to such an aggressive intervention from the family and the healthcare team. However, predictors of prognosis have been identified and some studies have concluded that advanced age is not associated with poor outcomes. Decisions regarding management are more complex when dealing with the elderly but like very other patient, the approach should be patient-centered.

Keywords: Acute kidney injury; Continuous renal replacement therapy; Aged; Critical illness

\section{INTRODUCTION}

Elderly people, conventionally defined as a chronological age of 65 years or more, are currently the fastest-growing sector of the population in developed countries. Their risk of developing acute kidney injury (AKI) is increased by age-related physiological changes, lower renal reserves, and multiple comorbidities that render them more susceptible to acute renal impairment. In addition, elderly patients typically take more medications and undergo more procedures, which may endanger their renal function. Hence, AKI is generally more common among the elderly. Few studies have reported predictors of AKI in this population. A retrospective study of 533 elderly patients ( $\geq 65$ years) used frailty, a comprehensive geriatric assessment, to predict AKI development. The frailest of the subjects were at increased risk for AKI (hazard ratio [HR], 3.536; $p=0.002)[1]$.
Depending on its severity, AKI may necessitate renal replacement therapy (RRT). The RRT modality most appropriate for critically ill patients with AKI has been debated. In intensive care unit (ICU) patients with hemodynamic instability, continuous renal replacement therapy (CRRT) is recommended because of its superior hemodynamic tolerability $[2,3]$. CRRT also has less of an effect on intracranial pressure, which makes it more suitable for patients with acute brain injury and cerebral edema [2-4].

In Denmark, the incidence of CRRT use in persons $>75$ years of age has increased substantially from 23 per million in 2000 to 213 per million in 2012. Indeed, the increase in the incidence of dialysis-requiring AKI is greatest among elderly patients [5]. In South Korea, the use of CRRT among the elderly has increased over time [6]. Similarly, according to data from the nationwide administrative database of Japan, the mean age of ICU patients who have undergone RRT increased from 64.75 
to 68.7 years over a 10-year period ( $p$ for trend < 0.01) [7].

For this review, we searched the PubMed database using the following terms: "continuous renal replacement therapy," "acute kidney injury," "elderly," and "critically ill." We also searched the reference lists of the articles identified. This review focuses on CRRT as a therapeutic intervention for critically ill elderly patients with AKI. Due to the scarcity of data on CRRT use in the elderly, we also review related data on the principles of CRRT performance in critically ill adults.

\section{CAUSES OF AKI IN THE ELDERLY}

The etiology of AKI may be categorized as pre-renal, renal, or post-renal. In the elderly, the causes of pre-renal AKI include volume depletion and decreased effective arterial blood volume, causing renal hypoperfusion. Vomiting, diarrhea, and excessive diuretic use cause AKI more frequently and rapidly in the elderly due to the age-related decline in the glomerular filtration rate (GFR), decreased renal reserves, and impaired autoregulation. Renal autoregulation is affected by drugs commonly used by the elderly, such as nonsteroidal anti-inflammatory drugs (NSAIDs), angiotensin converting enzyme (ACE) inhibitors, and angiotensin II blockers (Fig. 1) [8].

Acute tubular necrosis (ATN) is the most common form of intrinsic AKI among hospitalized patients. The leading precipitating factor for ATN is sepsis, which is a frequent reason for admission among the elderly. In a review of 200 elderly patients with AKI in Brazil, the most common AKI etiology was ATN associated with sepsis (48.1\%) [9]. In a retrospective study of 381 elderly patients $>80$ years of age, the majority had intrinsic AKI (53.5\%), mostly attributable to shock, or pre-renal AKI (24.1\%) secondary to dehydration and heart failure [10]. Funk et al. [11] reported that patients $>80$ years of age more frequently suffer from circulatory AKI secondary to hypovolemia or shock. In Gong et al. [12], the majority of AKI (53.34\%) in patients $\geq 65$ years of age was caused by ischemia. Other intrinsic causes of AKI in the elderly are acute interstitial nephritis, usually due to hypersensitivity to medications, particularly antibiotics and NSAIDs; renal vascular diseases; and glomerulonephritis.

The most common causes of post-renal AKI in the elderly are benign prostatic hyperplasia or prostate

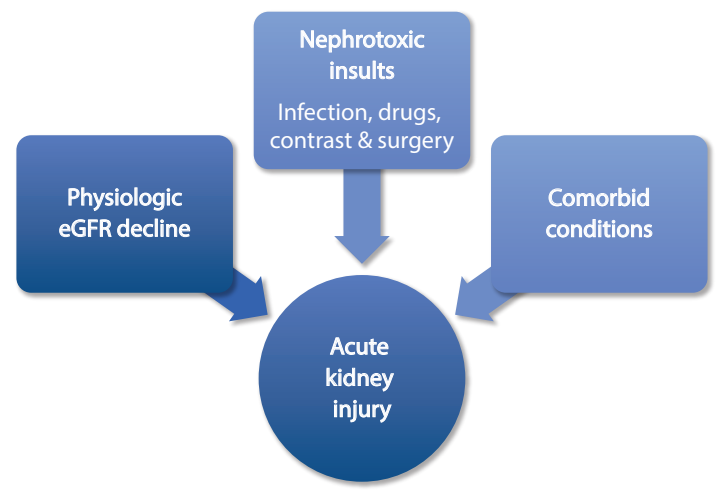

Figure 1. Risk factors for acute kidney injury in the elderly. eGFR, estimated glomerular filtration rate.

cancer in males and retroperitoneal or pelvic malignancies, such as ovarian or uterine cancer, in females $[8,13]$.

\section{INDICATIONS FOR CRRT IN THE ELDERLY}

Acute RRT is required GFR in cases of AKI presenting with refractory volume overload, intractable metabolic acidosis and hyperkalemia, and uremia [2-4]. However, in cases of severe AKI, RRT is often initiated before the onset of these conventional indications for RRT. Patients who develop anuric AKI unresponsive to acute interventions and patients intoxicated with dialyzable substances, such as lithium and salicylates, are also subjected to acute RRT. The decision to start RRT for elderly AKI patients should be based on the severity of organ failure and the trajectory of the disease course [14].

\section{TIMING AND DOSAGE OF CRRT IN THE ELDERLY}

Most systematic reviews and observational studies on the timing of CRRT initiation suggest that outcomes are improved if CRRT is initiated earlier. However, the optimal timing of CRRT initiation remains controversial.

In Park et al. [15], an early CRRT group had significantly better survival than a late-CRRT group $(p<0.01)$, consistent with Iwagami et al. [16], which reported that later CRRT initiation is associated with higher mortality $(p<0.01)$.

Two randomized trials have addressed the optimal 
timing of RRT initiation, and have reported conflicting results. The Effect of Early vs. Delayed Initiation of Renal Replacement Therapy on Mortality in Critically Ill Patients with Acute Kidney Injury (ELAIN) included 231 critically ill adult AKI patients who underwent CRRT and reported a significant benefit for early CRRT initiation in terms of the 9o-day mortality rate (39.3\% vs. $54.7 \%$; $\mathrm{HR}, 0.66$; $95 \%$ confidence interval [CI], 0.45 to $0.97 ; p=$ 0.03), renal function recovery rate (53.6\% vs. $38.7 \%$; odds ratio [OR], $0.55 ; 95 \% \mathrm{CI}, 0.32$ to $0.93 ; p=0.02$ ), and length of hospital stay (51 days vs. 82 days; HR, 0.34; 95\% CI, 0.22 to $0.52 ; p<0.001)[17]$. The Artificial Kidney Initiation in Kidney Injury (AKIKI) trial was a multicenter study of 620 critically ill AKI patients that reported no differences in the 6o-day mortality rate ( $48.5 \%$ vs. $49.7 \%, p=0.79$ ) or secondary endpoints including ventilator- and vasoactive-free days through day 28 , duration of ICU and hospital stay, and 6o-day dialysis [18]. These conflicting results may be due to differences in study design (predominantly post-surgical vs. medical patients, interval between early and delayed, 25.5 hours vs. 57 hours; RRT modality, CRRT vs. intermittent hemodialysis [IHD] and CRRT) and the relatively small sample sizes. Although both studies provided information on the optimal timing of RRT initiation, the findings are far from definitive. Further large, multicenter, randomized trials are needed to provide stronger evidence.

In a systematic review of nine randomized controlled trials (RTCs) of 1,627 critically ill adult patients (mean age, 59.4 to 68.4 years) with AKI who underwent RRT, earlier RRT initiation improved survival only in patients who underwent surgery (relative risk [RR], 0.78; 95\% CI, 0.64 to 0.95 ) or CRRT (RR, 0.80; 95\% CI, o.66 to 0.95) [19].

Liu et al. [20] analyzed data from the Program to Improve Care in Acute Renal Disease (PICARD), an observational cohort study of 618 adult ICU patients with a mean age of 59.5 years. Of the subjects, 398 were dialyzed, among whom CRRT was performed in 60\%. The RR of death associated with initiation of RRT at a higher blood urea nitrogen (BUN) level was 1.85 (BUN > 76 vs. $\mathrm{BUN} \leq 76 ; 95 \% \mathrm{CI}, 1.16$ to 2.96 ) [21].

A recent retrospective study of 158 septic shock patients with AKI found that cumulative mortality rate was significantly higher in patients in whom CRRT was initiated beyond 16.5 hours after AKI onset than in those in whom CRRT was started within 16.5 hours (HR,
1.009; 95\% CI, 1.003 to 1.014; $p=0.002$ ) [22].

Although several retrospective and observational studies have shown that early RRT initiation among adult AKI patients is correlated with improved outcomes $[15-17,22]$, further RCTs should focus on the optimal timing of CRRT initiation among the elderly. The decision to start RRT should depend on clinical assessment based on the patient's overall status and disease trajectory, rather than serum levels of creatinine or urine output alone.

The optimal intensity of CRRT in critically ill patients is also unclear. In a study of 41 elderly patients (80 to 100 years), prognosis differed significantly between replacement fluid doses of $<25$ and $>50 \mathrm{~mL} / \mathrm{kg} / \mathrm{hr}$ $(p<0.05)$ [23]. However, there were no significant differences between $<25$ and 25 to $50 \mathrm{~mL} / \mathrm{kg} / \mathrm{hr}$, or between 25-50 and > $50 \mathrm{~mL} / \mathrm{kg} / \mathrm{hr}$. Therefore, the authors' recommendation was to set the replacement fluid dosage to 25 to $35 \mathrm{~mL} / \mathrm{kg} / \mathrm{hr}$.

Most studies that have compared the outcomes of standard and higher dialysis doses have involved critically ill adult patients $>18$ years of age. In a prospective, randomized study, Ronco et al. [24] analyzed the effects of different CRRT doses on the survival of 425 patients with a mean age of 61 years. Survival in the $20 \mathrm{~mL} / \mathrm{kg} /$ $\mathrm{hr}$ group was lowest, while it did not significantly differ between the 35 and $45 \mathrm{~mL} / \mathrm{kg} / \mathrm{hr}$ groups [24]. The authors recommended that the rate of ultrafiltration should be $\geq 35 \mathrm{~mL} / \mathrm{kg} / \mathrm{hr}$ to improve survival.

To date, only two large multicenter RCTs have been conducted. A study by the Veterans Affairs/National Institutes of Health Acute Renal Failure Trial Network compared the outcomes of a more-intensive (IHD 6/ week or CRRT at $35 \mathrm{~mL} / \mathrm{kg} / \mathrm{hr}$ ) and less-intensive (IHD 3/week or CRRT at $20 \mathrm{~mL} / \mathrm{kg} / \mathrm{hr}$ ) treatment strategy. In it, 1,124 patients (age 59.7 \pm 15.3 years) were randomly assigned to the two groups. The authors reported no significant differences between the groups in terms of the rate of renal recovery and mortality [25]. In addition, the Randomized Evaluation of Normal versus Augmented Level (RENAL) Replacement Therapy Study of 1,464 CRRT patients (mean age, 64 years) did not find a reduction in the 9o-day mortality rate with higher effluent flow (40 mL/kg/hr vs. $25 \mathrm{~mL} / \mathrm{kg} / \mathrm{hr}$; OR, 1.0; 95\% CI, 0.81 to $1.23 ; p=0.99)$. There were also no significant differences in the rate of dialysis dependence between the 


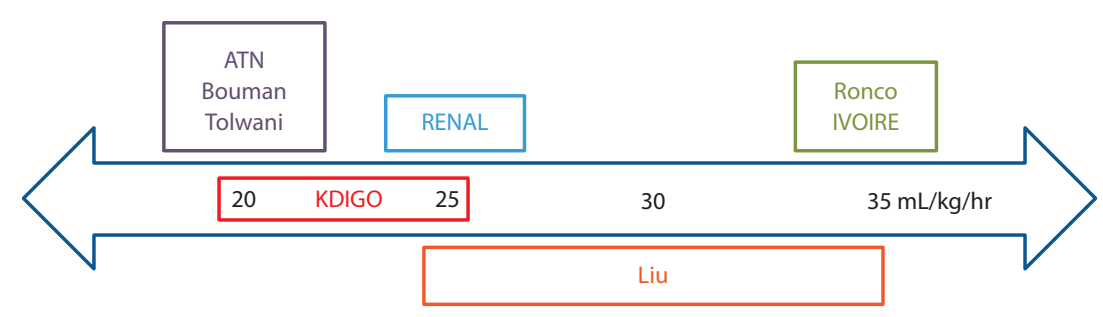

Figure 2. Continuous renal replacement therapy effluent dose recommendations. ATN, acute tubular necrosis; RENAL, Randomized Evaluation of Normal versus Augmented Level; KDIGO, Kidney Disease Improving Global Outcomes; IVOIRE, hIgh VOlume in Intensive Care.

two groups [26].

Bouman et al. [27] reported that a high ultrafiltrate volume does not improve survival or renal recovery, and Tolwani et al. [28] similarly found no significant differences in survival or renal recovery between highand standard-dose groups. The hIgh VOlume in Intensive Care (IVOIRE) study compared effluent flow rates of $70 \mathrm{~mL} / \mathrm{kg} / \mathrm{hr}$ ( $\mathrm{n}=66$; age, 58 to 77 years) and $35 \mathrm{~mL} /$ $\mathrm{kg} / \mathrm{hr}$ ( $\mathrm{n}=71$; age, 58 to 75 years) among septic shock patients, and reported no significant differences in 28-day mortality rate between the two groups [29].

At present, the Kidney Disease Improving Global Outcomes (KDIGO) recommends delivering an effluent volume of 20 to $25 \mathrm{~mL} / \mathrm{kg} / \mathrm{hr}$ [2]. However, the actual dose delivered may be substantially lower than the prescribed dose due to filter fouling and interruptions during CRRT, such as circuit changes and clotting [4]. Hence, attention should be paid to the actual delivered dose, particularly in the elderly because of their typically lower BMI and altered body composition (Fig. 2).

To the best of our knowledge, no RCT has determined the optimal CRRT dose in the elderly and so no recommendation on the appropriate effluent dose in the elderly can be made.

\section{ANTICOAGULATION DURING CRRT IN ELDERLY PATIENTS}

Anticoagulation in CRRT is essential, as clotting of the extracorporeal circuit is the most frequent complication. Several anticoagulants, such as heparin, low-molecular-weight heparin (LMWH), and trisodium citrate, have been used. The KDIGO guidelines recommend regional citrate anticoagulation ( $\mathrm{RCA}$ ) as the first choice in patients without contraindications to citrate [2]. RCA, rather than no anticoagulation, is also recommended for patients at high risk for bleeding [2].

In an open RCT that compared RCA to no anticoagulation, most of the patients were elderly and were admitted to the ICU after surgery [30]. There were no differences between the groups in terms of supporting time, cost, length of ICU and hospital stay, and ICU survival rate. No serious complications associated with RCA were noted.

In Garces et al. [31], the efficacy and safety of LMWH were compared to unfractionated heparin during CRRT. No major bleeding occurred; however, minor bleeding episodes were observed in $26 \%$ of the patients on enoxaparin. AKI increases the risk of LMWH accumulation because of its prolonged half-life, which is due to its renal clearance. LMWH accumulation might lead to excessive anticoagulation and an increased risk for bleeding [31].

At our institution, nafamostat mesilate (NM) is used for anticoagulation in patients at high risk for bleeding because of its short half-life. In Baek et al. [32], 243 patients (age, $56.5 \pm 13.7$ years) were started on CRRT without anticoagulation due to a high risk for bleeding. Later, 62 received NM because of frequent filter clotting while the other 181 patients did not receive anticoagulants. The average hemofilter lifespan in the NM group increased to 19.8 (interquartile range [IQR], 12.6 to 26.6) from 10.2 hours (IQR. 7.5 to 13.0) before NM treatment $(p<0.001)$, while the average hemofilter lifespan in the anticoagulation-free group was 27.5 hours (IQR, 17.5 to 38.2). There were no differences in 
red blood cell (RBC) transfusion frequency and number of RBC units transfused between the groups. The authors concluded that NM prolonged hemofilter lifespan without increasing bleeding or transfusion requirements and so can be used in patients with a high bleeding risk who have frequent filter clots.

Lee et al. [33] studied 73 patients at high risk for bleeding. Patients were randomized to receive NM (age, $52.97 \pm 13.94$ years) or no anticoagulation (age, $57.54 \pm 13.04$ years). There were no significant differences in the rate of transfusion or mortality between the two groups, and no adverse events related to NM were reported. Choi et al. [34] included patients at high risk for bleeding who received no anticoagulation $(\mathrm{n}=24$; age, $58.6 \pm 18$ years $)$ or $\mathrm{NM}(\mathrm{n}=31$; age, $63.6 \pm 11.5$ years $)$. The filter lifespan was longer in the NM group than in the no anticoagulation group (31.7 \pm 24.1 hours vs. $19.5 \pm 14.9$ hours, $p=0.035)$. There were no differences in the rate of transfusion, major bleeding complication, and survival between the two groups.

No study has compared anticoagulation methods in elderly patients on CRRT. The principles of anticoagulation are similar in the elderly and the general population; however, given their age, multiple comorbidities, and use of numerous medications, elderly people are at increased risk for bleeding [35]. When deciding which anticoagulant to use, we recommend considering previous use of anticoagulation medications due to other systemic diseases, and the history of bleeding. The choice of anticoagulant, each of which has advantages and disadvantages, must be tailored to the patient's characteristics. The healthcare team should be cautious and closely monitor for bleeding complications during CRRT.

\section{COMPLICATIONS OF CRRT IN THE ELDERLY}

Complications from vascular access, the procedure itself, and anticoagulation may arise during CRRT [36]. Unfortunately, no study has focused on the acute complications of CRRT in critically ill elderly patients (Table 1).

The complications of CRRT are similar in pediatric, adult, and elderly patients but physicians and nurses should be cautious when performing CRRT in the oldest patients due to their increased susceptibility
Table 1. Complications of continuous renal replacement therapy

\begin{tabular}{|c|c|}
\hline \multicolumn{2}{|l|}{ Vascular access } \\
\hline Catheter placement & $\begin{array}{l}\text { Arteriovenous fistula } \\
\text { Aneurysm } \\
\text { Thrombus formation } \\
\text { Hemorrhage } \\
\text { Hemothorax } \\
\text { Pneumothorax } \\
\text { Pericardial tamponade } \\
\text { Arrythmias } \\
\text { Air embolism }\end{array}$ \\
\hline Catheter dysfunction & $\begin{array}{l}\text { Recirculation of blood } \\
\text { Reduced solute clearance } \\
\text { Premature filter clotting }\end{array}$ \\
\hline \multicolumn{2}{|l|}{ Infection } \\
\hline Extracorporeal circuit & $\begin{array}{l}\text { Air embolism } \\
\text { Hypothermia } \\
\text { Bioincompatibility } \\
\text { Immunologic activation } \\
\text { Anaphylactoid reactions }\end{array}$ \\
\hline \multicolumn{2}{|l|}{ Anticoagulation } \\
\hline Heparin & $\begin{array}{l}\text { Bleeding, blood loss } \\
\text { Hemolysis } \\
\text { Thrombocytopenia } \\
\text { Thrombosis } \\
\text { Limb ischemia }\end{array}$ \\
\hline $\begin{array}{l}\text { Regional citrate } \\
\text { anticoagulation }\end{array}$ & $\begin{array}{l}\text { Hypocalcemia } \\
\text { Metabolic alkalosis } \\
\text { Hypernatremia } \\
\text { Citrate intoxication } \\
\text { Metabolic acidosis }\end{array}$ \\
\hline Lepirudin & Anaphylaxis \\
\hline Fluid removal & Hemodynamic instability \\
\hline $\begin{array}{l}\text { Electrolyte and } \\
\text { acid-base }\end{array}$ & $\begin{array}{l}\text { Increased phosphate clearance } \\
\text { Hypomagnesemia } \\
\text { Hypocalcemia } \\
\text { Hypokalemia } \\
\text { Hyponatremia, hypernatremia } \\
\text { Alkalemia }\end{array}$ \\
\hline Nutrition & $\begin{array}{l}\text { Amino acid and nutrient loss } \\
\text { Depletion of water-soluble } \\
\text { vitamins and trace minerals } \\
\text { Poor glycemic control }\end{array}$ \\
\hline Drug removal & $\begin{array}{l}\text { Increased clearance } \\
\text { Antibiotics } \\
\text { Vasopressors }\end{array}$ \\
\hline Delayed renal recovery & \\
\hline
\end{tabular}

brought about by age-related physiological changes. 
These changes include a decrease in muscle mass and lean body mass due to a $10 \%$ to $15 \%$ reduction in total body water; and decreased organ function, such as decreased protein production by the liver and decreased renal and hepatic clearance of medications, which make the elderly more susceptible to the nephrotoxicity of certain drugs. Elderly patients also have a higher incidence of metabolic diseases such as diabetes mellitus and hypertension, cardiovascular diseases, malignancies, and urinary obstructive diseases, increasing their exposure to nephrotoxic procedures and medications. They are thus at greater risk for hemodynamic instability, electrolyte disorders, and metabolic complications caused by CRRT and the toxicity of the anticoagulants used during CRRT.

\section{POST-CARDIOVASCULAR SURGERY}

Cardiovascular surgery is associated with a high risk for postoperative AKI. In recent years, cardiovascular surgery has been performed more frequently in older patients. A retrospective chart review by Van Den Noortgate et al. [37] analyzed data from 82 post-cardiac surgery adult patients who developed AKI and subsequently required RRT (CRRT or IHD). The population was divided into two groups according to age: younger ( $<70$ years; $\mathrm{n}=42$; mean age, $59 \pm 10$ years) and elderly ( $\geq$ 70 years; $n=40$; mean age, $76 \pm 4$ years). The mortality rate of the two groups was comparable (50\% vs. $61.9 \%$ ). Mortality in the elderly group was correlated with hypotension 24 hours before starting RRT, mechanical ventilation, and multiorgan failure [37].

A retrospective cohort study in Japan investigated the long-term outcomes among 144 elderly post-cardiovascular surgery patients aged 64 to 79 years who underwent CRRT postoperatively and survived to 90 days following hospital discharge [38]. Among the 144 survivors, $9 \%$ had dialysis-dependent stage renal disease (ESRD) and $25 \%$ died during the observation period. Those who eventually required chronic dialysis had a significantly lower preoperative estimated GFR (eGFR). Hypertension and an eGFR of $<30 \mathrm{~mL} / \mathrm{min} / 1.73 \mathrm{~m}^{2}$ at discharge were significantly associated with decreased renal survival. In addition, age $\geq 75$ years was significantly associated with worse long-term survival (HR, 2.1;
95\% CI, 1.0 to $4.6 ; p=0.04)$. A retrospective cohort study in Singapore analyzed 55 patients, with a median age of 67 years, who required acute RRT (CRRT or sustained low-efficiency dialysis) after coronary artery bypass surgery [39]. Overall, 19 of the patients died in hospital, and 33 showed renal recovery at the time of discharge. Survivors were followed up for a median of 44.2 months. Among the 36 survivors, 14 had chronic kidney disease (CKD) progression, six of whom were dialysis-dependent. In that study, lower preoperative eGFR (20.4 mL/ $\min / 1.73 \mathrm{~m}^{2}$ vs. $39.9 \mathrm{~mL} / \mathrm{min} / 1.73 \mathrm{~m}^{2}, \mathrm{p}=0.027$ ) was associated with CKD progression.

Data from these studies can be used to identify patients who are likely to develop immediate and longterm complications of AKI post-cardiovascular surgery. Patients with an eGFR $<30 \mathrm{~mL} / \mathrm{min} / 1.73 \mathrm{~m}^{2}$ at hospital discharge will benefit from nephrology follow-up and should be closely monitored for deterioration of renal function.

\section{MORTALITY, DIALYSIS DEPENDENCE, AND RISK FOR CHRONIC KIDNEY DISEASE}

The association between age and the outcome of ICU patients has been extensively studied. The mortality rate among elderly patients who develop AKI is high. Several parameters are considered predictors of prognosis. Liu et al. [23] reported that prognosis was significantly correlated with the number of involved organs, Acute Physiologic Assessment and Chronic Health Evaluation (APACHE) II score, mechanical ventilation, and hypoalbuminemia. Patients with an APACHE II score of $\leq 25$ points had a risk coefficient of $0.6 \pm 0.08$ (no mortality), while those with a score of $\geq 36$ points had a risk coefficient of $0.92 \pm 0.01$ and a mortality rate of $100 \%$.

In a Japanese study by Iwagami et al. [16], the inhouse mortality rate of elderly patients on CRRT was $50.6 \%$, and was largely associated with the severity of illness at baseline, as evidenced by use of mechanical ventilation, vasoactive support, and blood transfusion. A single-center, retrospective cohort study of 562 patients aged $\geq 54$ years who underwent CRRT reported a short-term mortality rate (death during hospital stay or within 1 week of discharge) of 57.3\% [40]. In addition to 


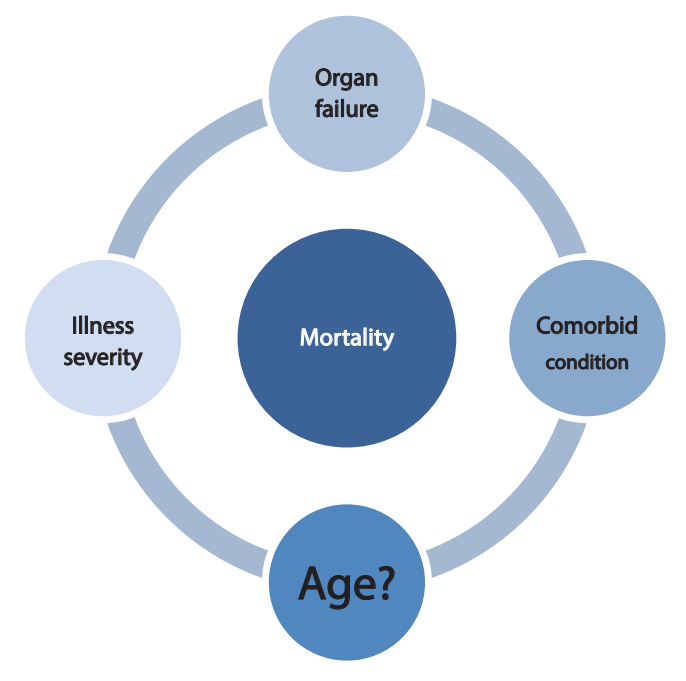

Figure 3. Predictors of mortality in the elderly.

age, a high Sequential Organ Failure Assessment (SOFA) score, acidemia, and prolonged prothrombin time were associated with a higher short-term mortality rate. The long-term mortality rate, or death at least 1 week after hospital discharge, was higher in the middle-old ( 75 to 84 years) and old-old ( $\geq 85$ years) cohorts compared to the young-old ( 65 to 74 years) cohort. The optimal cutoff age for predicting an increased long-term mortality rate was 72 years. Aside from age, a low BMI, congestive heart failure and/or liver cirrhosis, and sepsis at time of CRRT initiation were associated with a high longterm mortality rate. In a study of 725 AKI patients who received CRRT at Massachusetts General Hospital, 67\% were 50 to 79 years of age and $14 \%$ were $\geq 80$ years of age, and an age of $>60$ years was an independent risk factor for in-hospital mortality (OR, 1.9; 95\% CI, 1.3 to 2.7; $p=0.001)$ [41]. This finding is similar to that of Conroy et al. [42], that older patients ( $\geq 75$ years) have higher in-hospital ( $54.2 \%$ vs. $44 \%, p=0.02$ ) and 1-year (63.6\% vs. $50.6 \%, p=0.005)$ mortality rates.

Patients who have an episode of AKI are at higher risk for CKD and ESRD. In Ishani et al. [43], elderly patients ( $\geq 67$ years) with AKI were 6.74-fold more likely to develop ESRD than those without AKI, after adjusting for age, sex, race, diabetes, hypertension, and CKD. Moreover, among patients with AKI but no history of CKD, CKD occurred within 2 years in 72.1\%. In another retrospective study of 178 elderly ( $\geq$ 65 years) patients who underwent CRRT, recovery of kidney function was seen in only $6.18 \%$, while permanent loss of renal function occurred in $23.03 \%$ of the patients [44]. The predictors of a poor outcome were the initial creatinine level, GFR, 24 hours diuresis, and multiple organ failure. In a systematic review of 17 studies, 31.3\% of surviving elderly patients ( $\geq 65$ years) did not recover kidney function, compared to $26 \%$ of the younger patients (pooled RR, 1.28; 95\% CI, 1.06 to 1.55; $p<0.05)$ [45].

According to Wald et al. [46], dialysis-requiring RRT is associated with an increased risk of needing chronic dialysis, but not all-cause mortality. That study included more than 4,000 adult patients with dialysis-requiring AKI and 13,598 matches with neither AKI nor dialysis. The mean age of the subjects was 62 years. The incidence of chronic dialysis was 2.63 and 0.91 per 100 person-years among those with and without dialysis-requiring AKI, respectively (HR, 3.26; 95\% CI, 2.73 to 3.89). However, the risk of death was not significantly different between the two groups.

However, the poor outcomes in elderly AKI patients have not been consistent across all studies. A retrospective study in Germany of 424 patients reported that the prognosis of AKI in elderly patients was not necessarily worse than that in middle-aged patients [11]. That study stratified the subjects by age ( $\leq 80$ and $>80$ years) and analyzed death or dialysis dependence upon hospital discharge as the primary endpoint. The number of patients reaching the primary end point was similar in the two groups (20.4\% vs. $18 \%$; OR, 1.17 ; 95\% CI, 0.703 to 1.948). The authors concluded that the course and prognosis of AKI is not different in the elderly population. Conroy et al. [42] reported no significant difference in dialysis dependence in older compared to younger patients at ICU or on hospital discharge. Likewise, there were no significant differences in the risk for new ESRD between elderly and younger patients. In another previous study, prognosis was also not related to age [23].

Age affects the prognosis of patients who develop AKI, but the findings are not consistent. Several studies have failed to show a relationship between advanced age and poor outcome. Based on our review, advanced age can be considered a strong predictor of outcome; however, other parameters should be considered such as the severity of illness (i.e., APACHE II and SOFA scores, 
sepsis, need for blood transfusion) and the presence of multiorgan failure (i.e., use of mechanical ventilation and inotropes, heart and liver failure) $[13,16,21,44,47,48]$.

The most studied and consistent predictor of the development of CKD and ESRD after an episode of AKI is serum level of creatinine and eGFR [43,45,48,49].

Advanced age should not be used as a factor when making therapeutic decisions. Further studies involving more elderly patients are needed to reach definitive conclusions and propose recommendations (Fig. 3).

\section{WITHHOLDING CRRT}

Age may influence decision-making in regard to patient management and withholding of life-sustaining treatments. Because elderly are more susceptible to intra-dialytic hemodynamic, neurologic, and bleeding complications, therapeutic decisions tend to be more conservative. Elderly patients receive less-intensive treatment; more-invasive modalities are typically withheld $[40,50,51]$.

Older age is associated with a higher rate of withholding dialysis. Based on data from France, the oldest-old patients ( $\geq 80$ years) receive less renal support in the ICU than matched young-old patients (69 to 75 years) even after adjusting for severity of illness (adjusted odds ratio, 0.52; 95\% CI, o.41 to 0.66) [50]. In a similar study by Hamel et al. [51], the rate of withholding dialysis increased by $12 \%$ per decade of age (HR, 1.12; $95 \%$ CI, 1.06 to 1.19).

According to the Madrid Acute Renal Failure Study Group, age is not a particularly poor prognostic sign and so acute dialysis should not be withheld solely because a patient is $>80$ years of age [52]. In that study, risk for mortality was not significantly different among the groups ( $\geq 80$ years RR, 1.09; $p=0.562$, and 65 to 79 years $R R, 0.99 ; p=0.954$, compared to $<65$ years).

Several studies have found that age does not influence the outcome of CRRT, suggesting that age may not be an appropriate sole criterion for deciding whether to perform CRRT in critically ill elderly patients $[21,42,46]$. Physicians, the patient, and his/her family should consider all risk factors for complications and a poor outcome when making this decision. The number of affected/failing organs and the severity of acute disease, measured using APACHE II, are predictors of prognosis and should be taken into consideration. Decisions regarding withholding or discontinuation of CRRT should be made in the light of the overall prognosis and the goals of care.

\section{CONCLUSIONS}

The elderly is the fastest growing age group in developed countries, resulting in an increasing frequency of aggressive medical and surgical interventions. These interventions impose additional stress on the already physiologically deteriorating kidneys. Because of this, we have seen a steady increase in the incidence of AKI among the elderly in recent years.

Based on the articles reviewed, the most common etiology of AKI in the elderly is ATN secondary to sepsis and ischemia. Although data on the appropriate timing and intensity of CRRT in the elderly are scarce, the results of this review mirror the recommendations for the general population with AKI. Given the conflicting data on the optimal timing of CRRT initiation, the decision to start CRRT should not depend on serum levels of creatinine or urine output threshold but rather on the patient's medical condition and disease course. CRRT should be initiated earlier when life-threatening conditions arise. Based on the literature, more-intensive CRRT does not have a beneficial effect on mortality or renal recovery. A CRRT intensity of $>25 \mathrm{~mL} / \mathrm{kg} / \mathrm{hr}$ adds no significant benefit and exposes patients to risk for complications such as hypophosphatemia; hence, an effluent dose of $25 \mathrm{~mL} /$ $\mathrm{kg} / \mathrm{hr}$ is recommended. The choice for anticoagulant should be individualized according to the patient's characteristics, drug availability, and the physician's expertise. The healthcare team should be vigilant when CRRT is performed on the elderly, who are more vulnerable to complications. In elderly patients who develop AKI, subsequent monitoring of renal function is needed.

Once a diagnosis of AKI is established, supportive measures such as RRT should not be withheld because of a patient's advanced age, as recent literature does not support inferior outcomes in the elderly. Because reasonable outcomes are obtained in most elderly AKI patients, the physician should be focused on their recognition and management. 
Unfortunately, few data are available regarding the management of AKI in the elderly and even fewer on the therapeutic efficacy of CRRT in this subset of patients. Most of the data we reviewed were retrospective. We recommend that more prospective, randomized controlled studies be performed as the incidence of AKI has been increasing most rapidly in the elderly.

\section{Conflict of interest}

No potential conflict of interest relevant to this article was reported.

\section{REFERENCES}

1. Baek SH, Lee SW, Kim SW, et al. Frailty as a predictor of acute kidney injury in hospitalized elderly patients: a single center, retrospective cohort study. PLoS One 2016;11:e0156444.

2. Khwaja A. KDIGO clinical practice guidelines for acute kidney injury. Nephron Clin Pract 2012;120:c179-c184.

3. Ostermann M, Joannidis M, Pani A, et al. Patient selection and timing of continuous renal replacement therapy. Blood Purif 2016;42:224-237.

4. Tandukar S, Palevsky PM. Continuous renal replacement therapy: who, when, why, and how. Chest 2019;155:626-638.

5. Carlson N, Hommel K, Olesen JB, et al. Dialysis-requiring acute kidney injury in Denmark 2000-2012: time trends of incidence and prevalence of risk factors: a nationwide study. PLoS One 2016;11:eo148809.

6. Park S, Lee S, Jo HA, et al. Epidemiology of continuous renal replacement therapy in Korea: results from the National Health Insurance Service claims database from 2005 to 2016. Kidney Res Clin Pract 2018;37:119-129.

7. Miyamoto $\mathrm{Y}$, Iwagami M, Aso S, et al. Temporal change in characteristics and outcomes of acute kidney injury on renal replacement therapy in intensive care units: analysis of a nationwide administrative database in Japan, 2007-2016. Crit Care 2019;23:172.

8. Abdel-Kader K, Palevsky PM. Acute kidney injury in the elderly. Clin Geriatr Med 2009;25:331-358.

9. Yokota LG, Sampaio BM, Rocha E, Balbi AL, Ponce D. Acute kidney injury in elderly intensive care patients from a developing country: clinical features and outcome. Int J Nephrol Renovasc Dis 2017;10:27-33.

10. Akposso K, Hertig A, Couprie R, et al. Acute renal failure in patients over 80 years old: 25-years' experience. Intensive Care Med 2000;26:400-406.

11. Funk I, Seibert E, Markau S, Girndt M. Clinical course of acute kidney injury in elderly individuals above 80 years. Kidney Blood Press Res 2016;41:947-955.

12. Gong Y, Zhang F, Ding F, Gu Y. Elderly patients with acute kidney injury (AKI): clinical features and risk factors for mortality. Arch Gerontol Geriatr 2012;54:e47-e51.

13. Hsieh CW, Chen HH. Continuous renal replacement therapy for acute renal failure in the elderly. Int J Gerontol 2007;1:46-51.

14. Bagshaw SM, Chakravarthi MR, Ricci Z, et al. Precision continuous renal replacement therapy and solute control. Blood Purif 2016;42:238-247.

15. Park JY, An JN, Jhee JH, et al. Early initiation of continuous renal replacement therapy improves survival of elderly patients with acute kidney injury: a multicenter prospective cohort study. Crit Care 2016;20:260.

16. Iwagami M, Yasunaga $H$, Noiri E, et al. Current state of continuous renal replacement therapy for acute kidney injury in Japanese intensive care units in 2011: analysis of a national administrative database. Nephrol Dial Transplant 2015;30:988-995.

17. Zarbock A, Kellum JA, Schmidt C, et al. Effect of early vs delayed initiation of renal replacement therapy on mortality in critically ill patients with acute kidney injury: the ELAIN randomized clinical trial. JAMA 2016;315:21902199.

18. Gaudry S, Hajage D, Schortgen F, et al. Initiation strategies for renal-replacement therapy in the intensive care unit. N Engl J Med 2016;375:122-133.

19. Lai TS, Shiao CC, Wang JJ, et al. Earlier versus later initiation of renal replacement therapy among critically ill patients with acute kidney injury: a systematic review and meta-analysis of randomized controlled trials. Ann Intensive Care 2017;7:38.

20. Mehta RL, Pascual MT, Soroko S, et al. Spectrum of acute renal failure in the intensive care unit: the PICARD experience. Kidney Int 2004;66:1613-1621.

21. Liu KD, Himmelfarb J, Paganini E, et al. Timing of initiation of dialysis in critically ill patients with acute kidney injury. Clin J Am Soc Nephrol 2006;1:915-919.

22. Yoon BR, Leem AY, Park MS, Kim YS, Chung KS. Optimal timing of initiating continuous renal replacement therapy in septic shock patients with acute kidney injury. Sci Rep 2019;9:11981. 
23. Liu S, Cheng QL, Zhang XY, et al. Application of continuous renal replacement therapy for acute kidney injury in elderly patients. Int J Clin Exp Med 2015;8:9973-9978.

24. Ronco C, Bellomo R, Homel P, et al. Effects of different doses in continuous veno-venous haemofiltration on outcomes of acute renal failure: a prospective randomised trial. Lancet 2000;356:26-30.

25. VA/NIH Acute Renal Failure Trial Network, Palevsky $\mathrm{PM}$, Zhang JH, et al. Intensity of renal support in critically ill patients with acute kidney injury. N Engl J Med 2008;359:7-20.

26. RENAL Replacement Therapy Study Investigators, Bellomo R, Cass A, et al. Intensity of continuous renal-replacement therapy in critically ill patients. N Engl J Med 2009;361:1627-1638.

27. Bouman CS, Oudemans-Van Straaten HM, Tijssen JG, Zandstra DF, Kesecioglu J. Effects of early high-volume continuous venovenous hemofiltration on survival and recovery of renal function in intensive care patients with acute renal failure: a prospective, randomized trial. Crit Care Med 2002;30:2205-2211.

28. Tolwani AJ, Campbell RC, Stofan BS, Lai KR, Oster RA, Wille KM. Standard versus high-dose CVVHDF for ICU-related acute renal failure. J Am Soc Nephrol 2008;19:1233-1238.

29. Joannes-Boyau O, Honore PM, Perez P, et al. High-volume versus standard-volume haemofiltration for septic shock patients with acute kidney injury (IVOIRE study): a multicenter randomized controlled trial. Intensive Care Med 2013;39:1535-1546.

30. Gao J, Wang F, Wang Y, Jin D, Tang L, Pan K. A mode of CVVH with regional citrate anticoagulation compared to no anticoagulation for acute kidney injury patients at high risk of bleeding. Sci Rep 2019;9:6607.

31. Garces EO, Victorino JA, Thome FS, et al. Enoxaparin versus unfractioned heparin as anticoagulant for continuous venovenous hemodialysis: a randomized open-label trial. Ren Fail 2010;32:320-327.

32. Baek NN, Jang HR, Huh W, et al. The role of nafamostat mesylate in continuous renal replacement therapy among patients at high risk of bleeding. Ren Fail 2012;34:279-285.

33. Lee YK, Lee HW, Choi KH, Kim BS. Ability of nafamostat mesilate to prolong filter patency during continuous renal replacement therapy in patients at high risk of bleeding: a randomized controlled study. PLoS One 2014;9:e108737.
34. Choi JY, Kang YJ, Jang HM, et al. Nafamostat mesilate as an anticoagulant during continuous renal replacement therapy in patients with high bleeding risk: a randomized clinical trial. Medicine (Baltimore) 2015;94:e2392.

35. Quinn GR, Fang MC. How can I predict bleeding in my elderly patient taking anticoagulants? Cleve Clin J Med 2016;83:345-348.

36. Finkel KW, Podoll AS. Complications of continuous renal replacement therapy. Semin Dial 2009;22:155-159.

37. Van Den Noortgate N, Mouton V, Lamot C, et al. Outcome in a post-cardiac surgery population with acute renal failure requiring dialysis: does age make a difference? Nephrol Dial Transplant 2003;18:732-736.

38. Sueyoshi K, Watanabe Y, Inoue T, Ohno Y, Nakajima H, Okada H. Predictors of long-term prognosis in acute kidney injury survivors who require continuous renal replacement therapy after cardiovascular surgery. PLoS One 2019;14:eo211429.

39. Lim CC, Tan CS, Chia CM, et al. Long-term risk of progressive chronic kidney disease in patients with severe acute kidney injury requiring dialysis after coronary artery bypass surgery. Cardiorenal Med 2015;5:157-163.

40. Rhee H, Jang KS, Park JM, et al. Short- and long-term mortality rates of elderly acute kidney injury patients who underwent continuous renal replacement therapy. PLoS One 2016;11:e0167067.

41. Allegretti AS, Steele DJ, David-Kasdan JA, Bajwa E, Niles JL, Bhan I. Continuous renal replacement therapy outcomes in acute kidney injury and end-stage renal disease: a cohort study. Crit Care 2013;17:R109.

42. Conroy M, O'Flynn J, Marsh B. Mortality and long-term dialysis requirement among elderly continuous renal replacement therapy patients in a tertiary referral intensive care unit. J Intensive Care Soc 2019;20:138-143.

43. Ishani A, Xue JL, Himmelfarb J, et al. Acute kidney injury increases risk of ESRD among elderly. J Am Soc Nephrol 2009;20:223-228.

44. Prskalo M, Racki V, Dorcic G, Devcic B, Racki S. Continuous renal replacement therapy in elderly patients with acute kidney injury. Acta Med Croatica 2017;71:33-37.

45. Schmitt R, Coca S, Kanbay M, Tinetti ME, Cantley LG, Parikh CR. Recovery of kidney function after acute kidney injury in the elderly: a systematic review and meta-analysis. Am J Kidney Dis 2008;52:262-271.

46. Wald R, Quinn RR, Luo J, et al. Chronic dialysis and death among survivors of acute kidney injury requiring dialysis. 
JAMA 2009;302:1179-1185.

47. Kee YK, Kim D, Kim SJ, et al. Factors associated with early mortality in critically ill patients following the initiation of continuous renal replacement therapy. J Clin Med 2018;7:E334.

48. Wu L, Zhang P, Yang Y, et al. Long-term renal and overall survival of critically ill patients with acute renal injury who received continuous renal replacement therapy. Ren Fail 2017;39:736-744.

49. Macedo E, Zanetta DM, Abdulkader RC. Long-term follow-up of patients after acute kidney injury: patterns of renal functional recovery. PLoS One 2012;7:e36388.

50. Boumendil A, Aegerter P, Guidet B; CUB-Rea Network.
Treatment intensity and outcome of patients aged 80 and older in intensive care units: a multicenter matched-cohort study. J Am Geriatr Soc 2005;53:88-93.

51. Hamel MB, Teno JM, Goldman L, et al. Patient age and decisions to withhold life-sustaining treatments from seriously ill, hospitalized adults. SUPPORT Investigators. Study to Understand Prognoses and Preferences for Outcomes and Risks of Treatment. Ann Intern Med 1999;130:116-125.

52. Pascual J, Liano F. Causes and prognosis of acute renal failure in the very old. Madrid Acute Renal Failure Study Group. J Am Geriatr Soc 1998;46:721-725. 